\title{
A 6 year study of mammographic compression force: practitioner variability within and between screening sites.
}

\section{Abstract}

\section{Background}

The application of compression force in mammography is more heavily influenced by the practitioner rather than the client. This can affect client experience, radiation dose and image quality. This research investigates practitioner compression force variation over a six year screening cycle in three different screening units.

\section{Methods:}

Data were collected from three consecutive screening events in three breast screening sites. Recorded data included: practitioner code, applied compression force $(\mathrm{N})$, breast thickness $(\mathrm{mm}), \mathrm{BI}-\mathrm{RADS}_{\circledast}$ density category. Exclusion criteria included: previous breast surgery, previous/ongoing assessment and breast implants. 975 clients (2925 client visits, 11,700 mammogram images) met inclusion criteria across three sites. Data analysis assessed practitioner and site variation of compression force and breast thickness.

\section{Results:}

Practitioners across three breast screening sites behave differently in the application of compression force. Two of the three sites demonstrate variability within themselves though they demonstrated no significant difference in mean, first and third quartile compression force and breast thickness values $\mathrm{CC}(p>0.5)$, $\mathrm{MLO}(\mathrm{p}>0.1)$ between themselves. However, in the third site, where mandate dictates a minimum compression force is applied, greater consistency was demonstrated between practitioners and clients; a significant difference in mean, 
first and third quartile compression force and breast thickness values $(p<0.001)$ was demonstrated between this site and the other two sites.

\section{Conclusion:}

Variability within these two sites and between the three sites could result in variations. Stabilisation of these variations may have a positive impact on image quality, radiation dose reduction, re-attendance levels and potentially cancer detection. The large variation in compression forces could negatively impact on client experience between the units and within a unit.

Further research is required to establish best practice guidelines for compression force within mammography.

\section{Advances in knowledge:}

Practitioners vary in the compression forces they apply to clients over sequential screening attendances. Establishing better practice guidance could help to minimise this problem.

Keywords: Compression force, Breast compression, Compression variability 


\section{Introduction}

It is acknowledged that one of the most important factors in determining the success of a screening programme is screening uptake ${ }^{1,2}$. The causes of any non-uptake are multifactorial. A systematic review in 2013 measured the extent of non-uptake. This review indicated clients not re-attending for screening because of breast pain from prior mammography was a significant issue ${ }^{3}$. Whelehan and colleagues suggested that between 47,000 and 77,000 women within England do not re-attend for breast screening in a year due to pain directly related to a previous mammogram ${ }^{3}$.

Pain from mammography can arise from the application of compression force ${ }^{3}$. It has also been identified that the position of the breast under the mammography compression paddle can directly affect the amount of pressure in different portions of the breast ${ }^{4}$ with potential for direct association with increased breast pain.

Quality assurance standards within the National Health Service Breast Screening Programme (NHSBSP) are essential to ensure its continued effectiveness. The $2012^{5}$ annual review of breast screening highlighted that 'ultimately decisions based around screening programmes must be evidence based' and that it should be 'a first class system ensuring excellent training for all professional staff'. It seems extraordinary that such a service has no standards or guidelines on the application of compression force other than a statement 'the force of the compression on the $x$ ray machine should not exceed 200 Newtons $(\mathrm{N})^{6}$ with various proposed descriptors such as 'taut to touch' or 'until the skin blanches' ${ }^{7-11}$. 
This research investigates practitioner compression force variation over a six year screening cycle in three different screening units. It builds on earlier research, which was single centre. Previous research ${ }^{12,13}$ identified practitioner variability in compression force application during mammography imaging within a single NHSBSP screening programme. The current research includes two additional regional breast screening services located in the North of England (UK).

\section{Materials / Method}

Hospital (service evaluation) and University ethics committees approved access to a sample of 1500 screening events at each screening unit (a screening event is defined as one mammogram series which includes four images). In order to exclude mammography machine variability ${ }^{14}$ as a confounding factor in terms of data quality, data was gathered from one mammogram machine at each location (GE Seno Essential, Lorad Mk4 and Siemens Mammomat 3000). The three analogue mammogram machines were operated within NHSBSP and manufacturer specifications ${ }^{15,16}$ during the study period. The study period was for a consecutive six year period; only analogue images were included as NHSBSP screening sites had not been converted to digital technology for a six year period at the time of the study. Design characteristics of compression paddles tend to be similar between analogue and digital units, though it should be noted that recently paddles on the latter have started to introduce changes to their design.

\subsection{Client Sample}

Data were gathered retrospectively at all three sites from clients who attended three consecutive screening events. Only three screening events could be included as the required data for this study was unavailable prior to 2004 at certain screening sites. 
Identification of clients was through consecutive stratified sampling. For inclusion each client had to have three consecutive screening events, with their first recorded mammogram experience as their first event. Each would have four standard projections acquired (left / right CC (cranial-caudal) and left / right MLO (mediolateral oblique). For each client the following information was recorded directly from the mammography image - size of film, breast compression force value in decaNewtons (daN) or Newtons $(\mathrm{N})$, compressed breast thickness $(\mathrm{mm})$ and the practitioner who performed the mammogram, coded for anonymity.

Breast density was established by 5 observers in the three screening units using the 4 point BI-RADS ${ }_{\circledast}$ scale (Breast Imaging Reporting and Data System) ${ }^{17}-$ BI-RADS $_{\circledast}$ $1<25 \%$ dense, $\mathrm{BI}-\mathrm{RADS}_{\circledast} 2: 25 \%-50 \%$ dense, $\mathrm{BI}-\mathrm{RADS}_{\circledast} 3: 51 \%-75 \%$ dense, and BI-RADS $_{\circledast} 4>75 \%$ dense. In order to establish inter and intra observer characteristics of the 5 observers for BI-RADS scoring, fifty film-screen mammograms were used ${ }^{18}$. These images comprised of left and right CC and MLO and were scored by each observer independently under the same viewing conditions; blinded to the findings of other observers. To provide data to assess intra-observer variability, mammography image sets were re-scored after an interval of at least two weeks, to minimise recall bias. Near complete intra-observer agreement (Kappa >0.81) and strong or above inter-observer variability was demonstrated (First score Fleiss kappa 0.77 second score 0.65$)^{18}$.

\subsection{Exclusion Criteria}

Exclusion criteria were established (Figure 1). Clients with less than or more than four standard projections were also excluded. Following application of exclusion 
criteria the number of clients remaining for analysis at each unit were: site $1=344^{[13]}$, site $2=325$, site $3=306$.

\subsection{Practitioners}

Practitioners at all sites consisted of staff working in the breast imaging department at the time of the study. The staff included a mixture of Advanced Practitioners, Mammographers and Assistant Practitioners, all are referred to as practitioners for the purposes of this study. Clients were imaged by similar numbers of trained practitioners at the three sites; 14 at site one, 11 at site two and 15 at site three.

\subsection{Recorded data}

Compression force and compressed breast thickness, together with practitioner details of those who performed the imaging were noted for all images.

\section{Results}

\subsection{Practitioners}

Firstly, analysis of practitioner grade between sites was compared (Table 1). The range of the number of clients the practitioners imaged at each site was: site one (10-146); site two (10-155); site three (12-139). The mean number of clients imaged by all practitioners at each site was, site one: (73.7), site two: (88.6), site three (61.2). The median number of clients imaged at each site was, site one: (73.5), site two: (100), site three:(75).

\subsection{BI-RADS Breast Density Classification}

The distribution of BI-RADS density within each site was assessed for similarity between sites by documenting the number of mammograms imaged per site in a percentage for each BI-RADS breast density category (Table 2). For the purposes of statistical analysis, combination of BI-RADS ${ }_{\circledast} 1$ and 2 (Group A) and also BI- 
$\operatorname{RADS}_{\circledast} 3$ and 4 (Group B) was required due to the low numbers of images in $\mathrm{Bl}$ $\operatorname{RADS}_{\circledast}$ group 1 with BI-RADS ${ }_{\circledast}$ group 4, having zero figures for some practitioners. Pearson Chi Squared test was used for the comparison of BI-RADS ${ }_{\circledast}$ Group A and Group B amongst sites. Pearson's $X^{2} 156$ (Group A) and 107 (Group B), (p $<0.0001)$ suggests there is a significant difference in the distribution of BI-RADS ${ }_{\circledast}$ grades between different sites.

Whilst it is recognised that this could be considered as a study limitation, it has been established previously ${ }^{12}$ that practitioners display the same compression behaviours across BI-RADS density classifications and do not necessarily vary their application of compression force according to breast density.

\subsection{Practitioner variability}

To establish practitioner variability, the mean compression values for all practitioners, at all sites, were analysed (Figure two and three). Compression force values varied across the three sites, with $\mathrm{CC}$ average at site one $86 \mathrm{~N}$, site two $84 \mathrm{~N}$, site three $125 \mathrm{~N}$. For the MLO, site one $97 \mathrm{~N}$, site two $88 \mathrm{~N}$, site three $132 \mathrm{~N}$. Analysis of variance (ANOVA) of mean compression force values of practitioners demonstrated a significant difference $(p<0.0001)$ between sites 'one and three', and 'two and three'. Sites 'one and two' demonstrated no significant difference (CC $p>0.5$, MLO $p>0.1$ ). These levels of significance hold true within each BI-RADS density classification.

First and third quartile results at all sites were analysed (table three). In CC and MLO, ANOVA of first and third quartile compression force levels of practitioners demonstrated a significant difference $(\mathrm{p}<0.0001)$ between sites 'one and three' and 
sites 'two and three'. Sites 'one and two' demonstrated no significant difference (first quartile $p>0.1$, third quartile $p>0.5$ ). This holds true within each BI-RADS grade. Having removed the outliers (see Figures 2 and 3), minimum and maximum compression force values for CC views ranged as follows: Site one $47 \mathrm{~N}$ to $122 \mathrm{~N}$ $(75 \mathrm{~N})$, site two $42 \mathrm{~N}$ to $114 \mathrm{~N}(72 \mathrm{~N})$, site three $103 \mathrm{~N}$ to $158 \mathrm{~N}(55 \mathrm{~N})$. For MLO: site one $65 \mathrm{~N}$ to $136 \mathrm{~N}(71 \mathrm{~N})$, site two $48 \mathrm{~N}$ to $139 \mathrm{~N}(91 \mathrm{~N})$, site three $103 \mathrm{~N}$ to $163 \mathrm{~N}(60 \mathrm{~N})$.

\subsection{Percentage changes in breast compression force}

Analysing the mean percentage change between minimum and maximum compression force values per client, from their three screening mammograms, establishes one aspect of variability from a client perspective.

The mean percentage change between minimum and maximum compression force was calculated for each BI-RADS grade for both CC and MLO (Figure Four). Average values of mean percentage change for each site for the MLO: site one $55 \%$, site two $66 \%$, site three $27 \%$ and the CC: site one $57 \%$, site two $60 \%$ and site three $26 \%$.

ANOVA was performed on percentage changes. For MLO, sites 'one and three' and 'two and three' demonstrated a significant difference $(p<0.0001)$ and this holds true within each BI-RADS grade. Sites one and two demonstrated no significant difference ( $p>0.2)$, this holds true for each BI-RADS grade. No significant difference was demonstrated between sites 'one and two' $(p>0.5)$. It can be concluded that site three displays low client variability over the three screens. 


\subsection{Breast Thickness}

Compressed breast thickness ranges at all sites were compared by mean, first and third quartile values for CC and MLO.

Mean compressed breast thickness values at all sites were analysed (Table four). Over the three screens, in both the CC and MLO, ANOVA of mean compressed breast thickness values of practitioners demonstrated a significant difference $(p<0.0001)$ between 'site one and three' and site 'two and three'. Site one and two demonstrated no significant difference in mean CC values of thickness $(p>0.5)$. This holds true within each BI-RADS grade. Practitioners at site three applied higher compression values and this would explain why the breast thicknesses at this site are smallest.

First and third quartile compressed breast thickness values at all sites were analysed (Table five). For both the CC and MLO , ANOVA demonstrated significant differences $(p<0.0001)$ in first and third quartile breast compressed thickness values between sites 'one and three' and sites 'two and three'. Site 'one and two' demonstrated no significant difference in values of thickness $(p>0.5)$. This holds true within each BI-RADS grade.

\section{Discussion}

\subsection{Compression force variability}

This research has demonstrated that the amount of breast compression force applied by practitioners is not consistent within and between three NHSBSP screening sites. 
For site one, within each of the three subgroups variability is low ${ }^{13,14}$. At site two practitioners apply compression force across a wide range of values and they do not fall into subgroups. Overall, practitioners from site one and site two apply compression forces within the same mean values, first and third quartiles and there is no statistical difference between them. Sites one and two permitted their practitioners to define their own compression force values, within NHSBSP maximum tolerance levels. Whilst there is no statistical difference between sites one and two, a client attending either or both of these sites would potentially be subject to large variations in compression force on subsequent visits. However, on average, for sites one and two, a client would have a lower level of compression force applied compared with site three. However for site three a client would likely have a higher though more consistent level of compression forced applied over time.

Site three had a protocol in place which mandates that a minimum level of $100 \mathrm{~N}$ compression force is used. Some sites within NHSBSP have protocols similar to this. Therefore, the lack of a consistent approach within NHSBSP exposes clients to variation in compression force if they moved between sites. It might be worthwhile speculating that higher compression force values could be associated with reduced client experience and pain and reduced re-attendance. Equally variability could also cause this problem too - perhaps even at lower levels of compression force.

It is also worth noting that no data exists to illustrate that image quality is better when compression forces of $100 \mathrm{~N}$ or higher are used, as in site three; rather anecdote dictates that higher compression forces are likely to result in better image quality. A pilot study ${ }^{19}$ identified no differences in image quality with higher 
compression forces, however the image quality scoring mechanism may not be sensitive enough to identify subtle changes in image quality.

A noted limitation of this study is that the three sites studied are located in the same geographical region and therefore practitioners could have been trained similarly, thereby reflecting a local variability problem. However, in 2013 Murphy and colleagues $^{20}$, from a UK-wide analysis of compression force behaviours, identified that practitioners vary in their approach to the application of compression force. This current study is therefore likely to reflect behaviour nationally.

\subsection{Breast thickness variability}

The inconsistency in compression force application across the three sites has a direct association with an inconsistency of compressed breast thickness values. Site one and two have similar means, first and third quartile compressed thickness values with no statistical difference $(p>0.5)$. Site three has significant differences in compressed breast thickness levels to the other two sites $(p<0.001)$; this has obvious direct implications for radiation dose and may have an impact on image quality - especially when sequential imaging comparison is considered. On this basis site three might be considered superior for consistency and dose minimisation.

\subsection{National standards}

From this and prior research ${ }^{13,14}$ there is a need for the NHSBSP to consider the introduction of national guidance on compression force levels. Hogg and colleagues $^{21}$ in 2013 highlighted minimum and cessation compression force levels for one mammography machine. They suggested that cessation should be 
considered based upon rate of change of compression force and thickness reduction, rather than by compression force alone.

Taking a different perspective, a recent study by de Groot and colleagues ${ }^{22}$ questioned if standardisation by compression force was meaningful and they suggested a focus towards pressure. They explained that clients with small breasts would experience more pressure than clients with large breasts with the same applied compression force. They suggested standardisation based upon pressure and this shows promise.

\subsection{Possible impact on client experience}

The findings of this research have possible implications for clients. These will be discussed in turn.

\subsubsection{Radiation Risk}

With respect to radiation risk there remain uncertainties about absolute cancer risk from low dose mammography screening. A recent report states that the risk of radiation induced cancer is approximately 1 in 20,000 per screening visit ${ }^{23}$. This equates to 154 cancers detected for every one induced and 80 lives saved for every life lost to radiation induced cancers ${ }^{23}$. Benefit thus exceeds risk. This research demonstrated that site three had lower breast thickness levels than the other two sites overall within the six year screening cycle $(p<0.001)$. Reducing breast thickness has potentially quantifiable reductions in radiation risks to clients within the screening programme.

\subsubsection{Image Comparison}

Direct comparison between images on successive screens is vital to ensure accurate visualisation of subtle changes within the breast. Direct comparison is not 
only essential within the same screening site but across the whole NHSBSP as clients can attend different sites. Our research has demonstrated compression force and breast thickness differences exist between and within sites, and the latter could influence image quality. If differences in quality exist for the same client then this could confound comparison of images on successive screens.

\subsubsection{Re-attendance}

Pain and non-re-attendance are related. Having a standardised approach to compression force levels within a specified range might improve client experience by offering them a consistent expectation and experience. Further research is needed into client pain and levels of applied compression force.

\section{Conclusion}

Our research demonstrates that practitioners across three breast screening sites behave differently in the application of compression force when undertaking mammography. Two of the three sites demonstrate variability. Variability within these two sites and between the three sites could result in variations in image quality, radiation dose together with client experience which in turn could influence re-attendance. When mandate dictates a minimum compression force standard this results in greater consistency between practitioners and clients. This may have a positive impact on image quality, radiation dose reduction and potentially cancer detection.

\section{Conflict of Interest Statement/Role of Funding}

The authors have no conflict of interest to declare. Part funding for the study was received by the Countess of Chester Breast Unit and Burnley General Breast Unit to cover associated staff costs whilst data collection ensued for this study. This funding 
was from the North West Regional Quality Assurance Reference Centre. The sponsors have had no role in study design, collection of data, analysis or interpretation of data, writing of the manuscript of decision to submit the manuscript.

\begin{tabular}{|l|c|c|c|c|}
\hline Site & Assistant & Radiographers & Advanced & Total Practitioners \\
\hline Site One & 2 & 10 & 2 & 14 \\
\hline Site Two & 0 & 9 & 2 & 11 \\
\hline Site Three & 2 & 8 & 5 & 15 \\
\hline
\end{tabular}

Table One: Practitioner Grade per Site

\begin{tabular}{|c|c|c|c|c|}
\hline Site & $\begin{array}{c}\% \text { mammograms } \\
\text { BI-RADS } 1\end{array}$ & $\begin{array}{c}\% \text { mammograms } \\
\text { BI-RADS } 2\end{array}$ & $\begin{array}{c}\% \text { mammograms } \\
\text { BI-RADS } 3\end{array}$ & $\begin{array}{c}\% \text { mammograms } \\
\text { BI-RADS } 4\end{array}$ \\
\hline One & 11 & 64 & 21 & 4 \\
\hline Three & 21 & 40 & 29 & 10 \\
\hline
\end{tabular}

Table Two: Percentage of Mammograms within each BI-RADS Breast Density Category

\begin{tabular}{|c|c|c|c|c|c|c|c|c|}
\hline & & & \multicolumn{3}{|c|}{ First Quartile } & \multicolumn{3}{|c|}{ Third Quartile } \\
\hline Site & $\begin{array}{l}\text { MLO } \\
\text { Compression } \\
\text { (N) }\end{array}$ & $S . D$ & $\begin{array}{l}\text { CC } \\
\text { Compression } \\
\text { (N) }\end{array}$ & $S . D$ & $\begin{array}{l}\text { MLO } \\
\text { Compression } \\
(N)\end{array}$ & $S . D$ & $\begin{array}{l}\text { CC } \\
\text { Compression } \\
(N)\end{array}$ & $S . D$ \\
\hline Site One & 84.85 & 21.63 & 75.5 & 17.07 & 106.1 & 26.07 & 92.7 & 22.87 \\
\hline Site Three & 118.21 & 12.75 & 111.99 & 10.09 & 144.34 & 14.65 & 135.41 & 15.25 \\
\hline
\end{tabular}

Table Three: First and Third Quartile Compression Forces all Sites

\begin{tabular}{|l|c|c|c|c|}
\hline Site & MLO Thickness & S.D & CC Thickness (mm) & S.D \\
\hline Site One & 53.8 & 13.7 & 50.9 & 11.3 \\
\hline Site Two & 57.9 & 12.2 & 56.8 & 10.9 \\
\hline Site Three & 47.1 & 12.7 & 43.5 & 10.5 \\
\hline
\end{tabular}

Table Four: Mean Breast Thickness Value $(\mathrm{mm})$ : Comparison all Sites

\begin{tabular}{|c|c|c|c|c|c|c|c|c|}
\hline & & & \multicolumn{3}{|c|}{ First Quartile } & \multicolumn{3}{|c|}{ Third Quartile } \\
\hline Site & $\begin{array}{l}\text { MLO } \\
\text { Thickness (m } \\
\text { m) }\end{array}$ & S.D & $\begin{array}{l}\text { CC } \\
\text { Thickness (m } \\
\text { m) }\end{array}$ & S.D & $\begin{array}{l}\text { MLO } \\
\text { Thickness (m } \\
\text { m) }\end{array}$ & S.D & $\begin{array}{l}\text { CC } \\
\text { Thickness (m } \\
\text { m) }\end{array}$ & S.D \\
\hline Site One & 44.55 & 3.43 & 43.56 & 2.86 & 63.6 & 3.80 & 59.73 & 2.54 \\
\hline Site Two & 49.78 & 2.94 & 50.46 & 3.02 & 65.36 & 3.08 & 62.61 & 2.58 \\
\hline Site Three & 38.23 & 3.70 & 36.32 & 2.66 & 56.52 & 2.85 & 50.74 & 2.91 \\
\hline
\end{tabular}

Table Five: First and Third Quartile Compressed Breast Thickness Value ( $\mathrm{mm})$ : Comparison all Sites 
Figure One: Exclusion Criteria

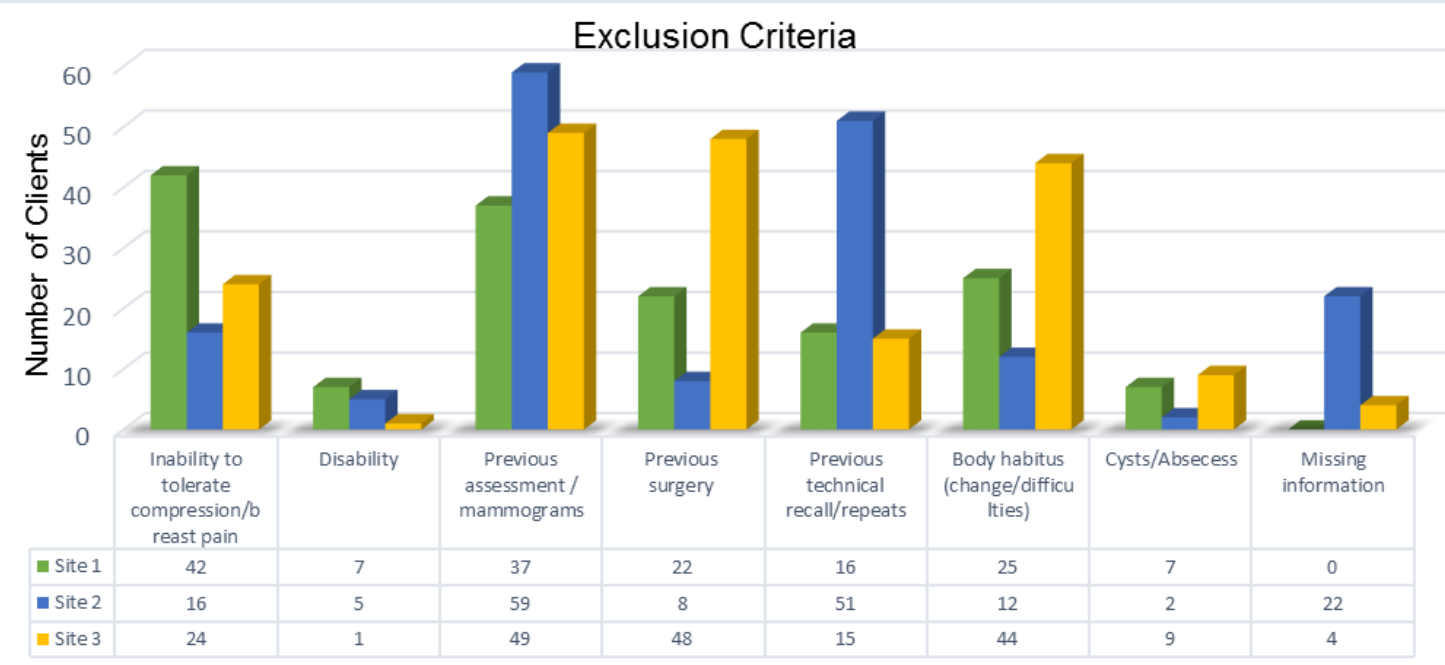

Figure Two: Mean Compression Force Values CC View

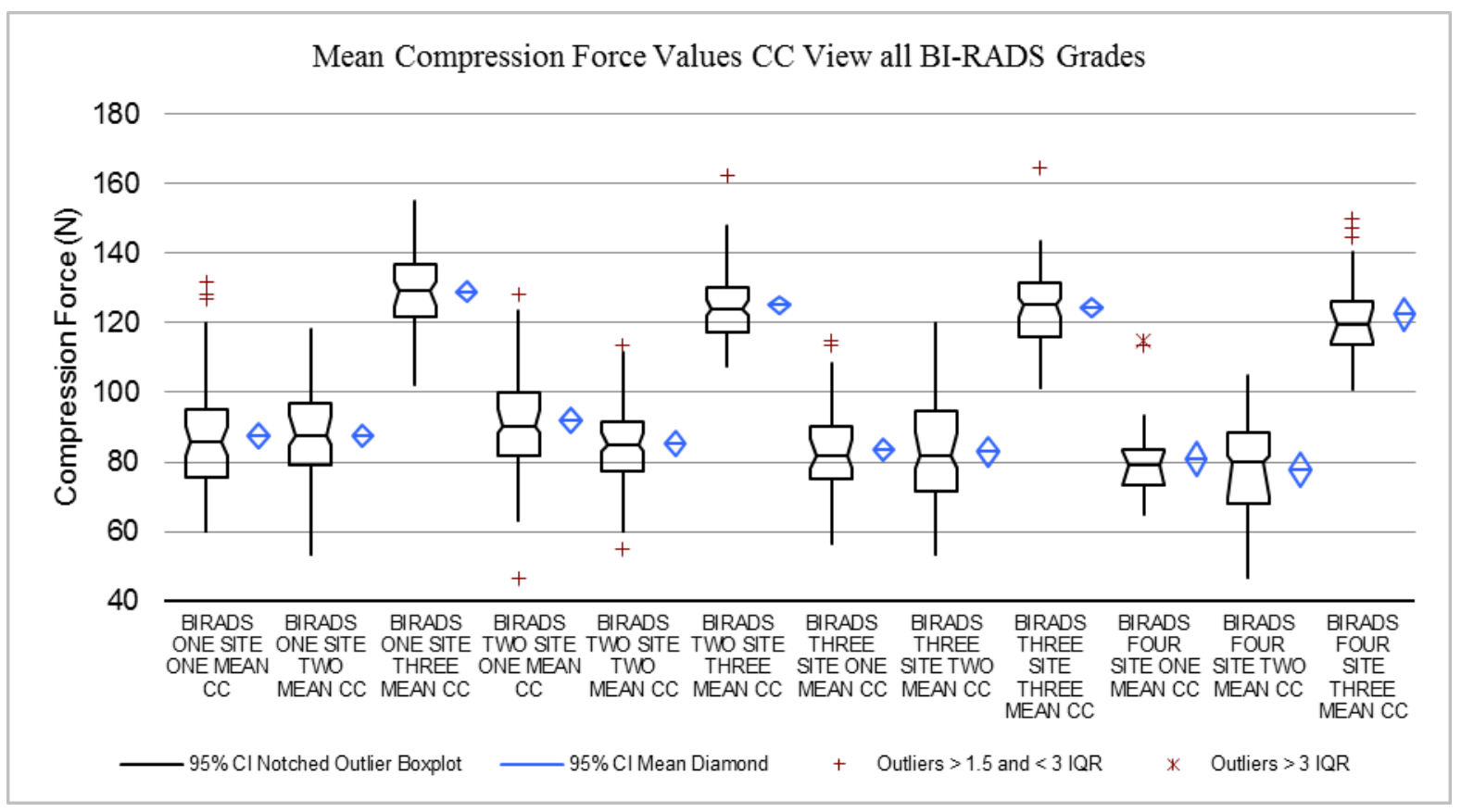




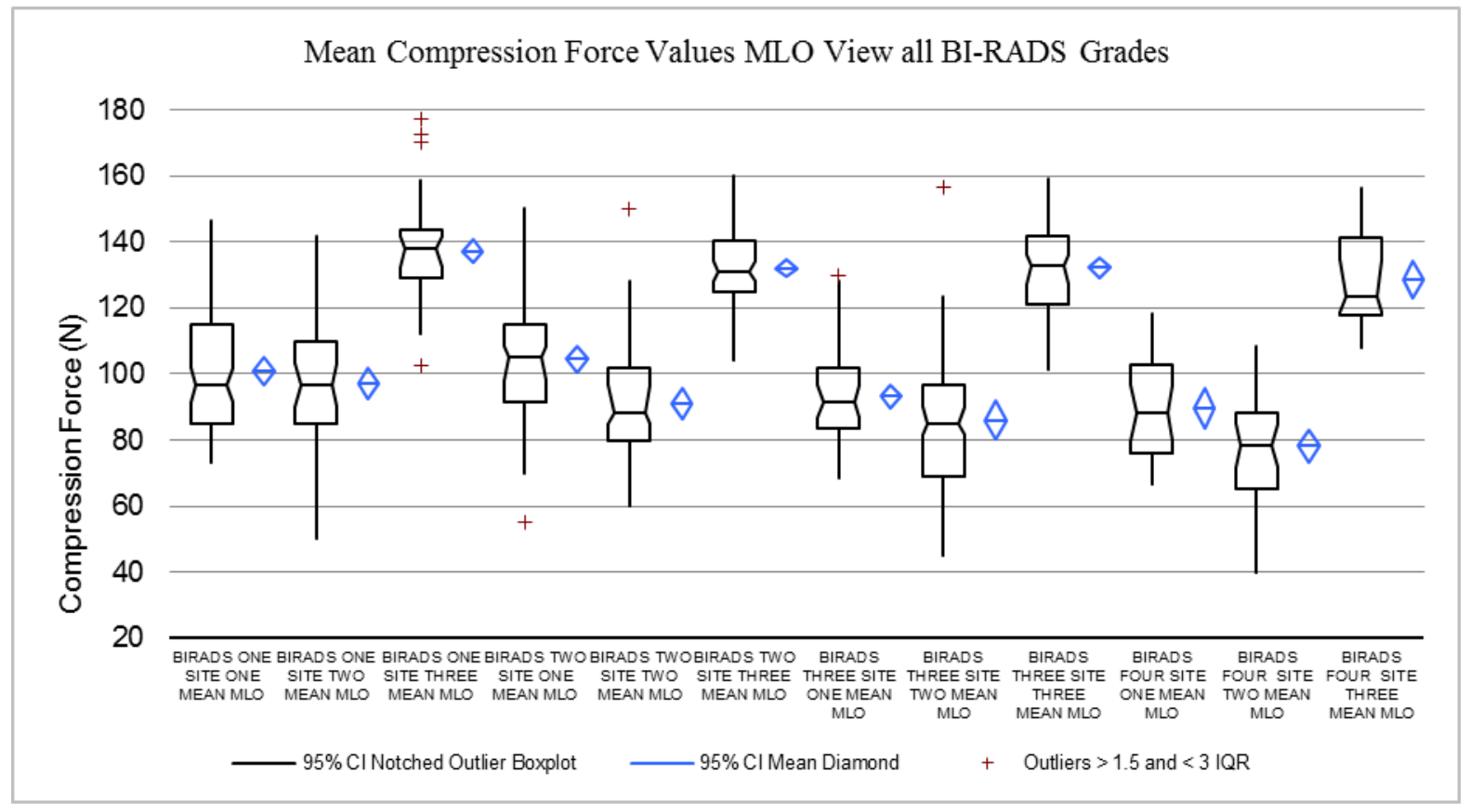

Figure Four: Overall Mean Percentage Change in Minimum and Maximum Compression Force Values over Three Screens

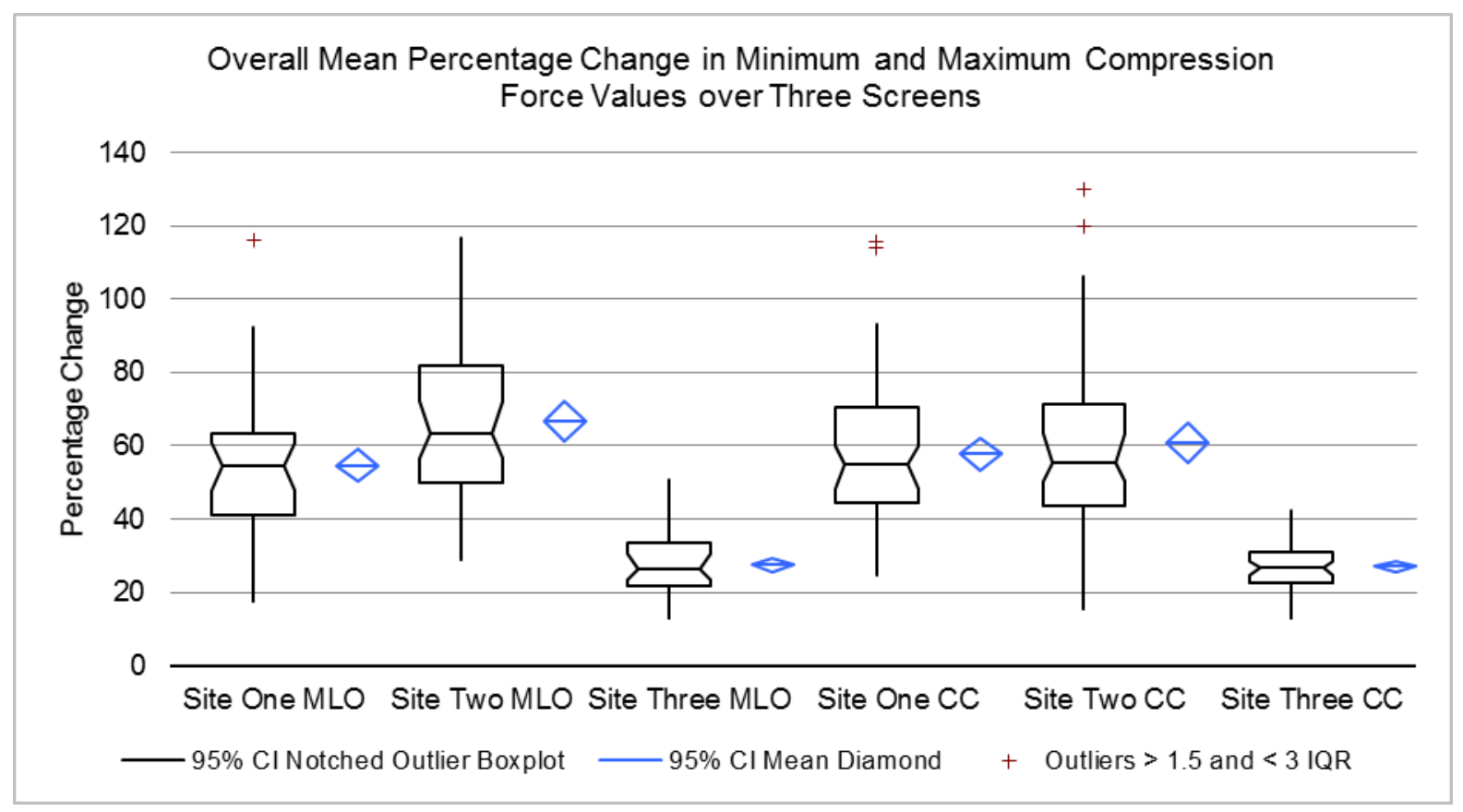




\section{References}

1. Marmot M, Altman DG, Cameron DA, Dewer JA, Thompson SG, Wilcox M. The benefits and harms of breast cancer screening: an independent review. The Lancet 2012; 380 (9855): 1778-86

2. Weller DP, Campbell C Br J Cancer. 2009 Dec 3;101 Suppl 2:S55-9. doi: 10.1038/sj.bjc.6605391. Uptake in cancer screening programmes: a priority in cancer control.

3. Whelehan P Evans A, Wells M, Macgillivray S. The effect of mammography pain on repeat participation in breast cancer screening: A systematic review. Breast 2013 Aug:22(4) 389-94

4. Smith $\mathrm{H}$, Hogg $\mathrm{P}$, Maxwell A, Mercer C, Szczepura K. An analysis of the compressed breast area and image receptor/compression paddle pressure balance in different mammographic projections. UKRC 2013 Publication.

5. NHS Breast Screening Programme 2012 Annual Review Published 2012 | ISBN 978-1-84463-093-6

6. NHSBSP 33. Quality assurance guidelines for medical physics services. $2^{\text {nd }}$ edn. June 2005; ISBN 1844630161

7. Long S. The handbook of mammography, $4^{\text {th }}$ edn. Edmonton: Mammography Consulting Services Ltd, 2000.

8. Wentz G. Mammography for radiologic technologist. New York: Mc Graw Hill, 1992.

9. Kopans D. Breast Imaging, $3^{\text {rd }}$ edn. Lippincott: Williams and Wilkins, 2007.

10. Eklund GW, Cardenosa G. The art of mammographic positioning. Breast Imaging: Current Status and Future Directions. Radiologic Clinics of North America. 1992; 30:21-53.

11.Poulos A, McLean D. The application of breast compression in mammography: a new perspective. Radiography. 2004; 10:131-137.

12. Mercer CE, Hogg P, Lawson R, Diffey J, Denton ERE. Practitioner compression force variability in mammography: a preliminary study. $\mathrm{Br} \mathrm{J}$ Radiol Feb 2013;86:20110596. 
13. Mercer C.E, Hogg P, Szczepura K, Denton E.R.E. Practitioner compression force variation in mammography: A 6-year study. Radiography 19 (2013) 200-206

14. Hauge I, Hogg P, Szczepura K, McGill GG, Connolly P, Mercer CE. The readout thickness versus the measured thickness for a range of screen film mammography and full-field digital mammography units, Medical Physics, 39, 1,2012

15. Report No. 89 (Revision of IPEM Report 59). The commissioning and routine testing of mammographic $x$-ray systems. Institute of physics and engineering in medicine (IPEM), 2005.

16.NHSBSP 63. Quality Assurance Guidelines for Mammography. April 2006; 42. ISBN 1844630285.

17. D'Orsi CJ, Bassett LW, Berg WA. Mammography, $4^{\text {th }}$ Edition. Breast Imaging Reporting and Data System: ACR BI-RADS ${ }_{\circledast}$. Reston VA: American College of Radiology, 2003.

18. Mercer C, Hogg P, Kelly J, Borgen R, Enion D, Hilton B, Millington S \& Whelehan $P$ (2013) A mammography image set for research purpose utilizing BI-RADS density classification. Radiologic Technology in press

19. Mercer C, Hogg, P,Cassidy S, Denton ERE, 2013. Does an increase in compression force really improve visual image quality in mammography? An initial investigation, 2013. Radiography Volume 19, 2013, Pages: 363-365

20. Murphy F.J. Nightingale J.M. Mackay S.M. Robinson L. Seddon D. Hogg P. Compression behaviours- An exploration of the beliefs and values influencing the application of breast compression during screening mammography, UKRC 2013

21. Hogg P, Taylor M, Szczupera K, Mercer C and Denton E, 2013. Pressure and breast thickness in mammography - an exploratory calibration study, British Journal of Radiology, 2013

22. De Groot JE, Broeders MJM, Branderhorst W, den Heeten GJ, Grimbergen CA. A novel approach to mammographic breast compression: Improved standardization and reduced discomfort by controlling pressure instead of force. Med. Phys. 40 (8), August 2013

23. The Royal College of Radiologists. Guidance on screening and symptomatic breast imaging. $3^{\text {rd }}$ Edition. London: The Royal College of Radiologists 2013, June http://www.rcr.ac.uk/docs/radiology/pdf/BFCR(13)5_breast.pdf 